\title{
HUMAN CAPITAL FORMATION AND USE IN BULGARIA*
}

\author{
A. Vladikov** \\ Department of Economics, Faculty of Economic and Social Sciences, University of Plovdiv, \\ Plovdiv, Bulgaria
}

\begin{abstract}
Purpose: The purpose of the paper is to focus on the Theory of Human Capital in order to reflect recent findings for the Bulgarian economy in terms of the relation "investment in higher education" - "returns on the labor market".

Methods: The method of the research is statistical observation, along with complex computational analysis, based on a three-year project [2007 - 2009] of a team of academic researchers from Bulgaria and on the PhD paper of Atanas I. Vladikov within the period [2010-2013].

Results: The results of the paper is demonstration of the true costs of educational attainment in higher schools of economics in Bulgaria, and other major market-demanded professionals, on the one hand. On the other hand, the paper investigates the issues of labor remuneration for professionals who have higher schools' academic degrees.

Conclusions: The conclusions of the paper are to outline whether the market of higher education in Bulgaria is competitive enough to produce highly qualified and highly paid professionals for the needs of the national and the European labor markets.
\end{abstract}

Key words: human capital, higher education, labor market

\section{INTRODUCTION}

Developing countries, such as Bulgaria, Romania, and some other former USSR-states, which have been already successful in their accession to the economy of the EU, managed to evolved for the last 20 years from command-driven to market driven economies. This transition was coupled with the fundamental change of comprehending how education of one man affects his lifetime decisions and drive for a better standard of living through successful career advancement on the labor market.

In terms of terminology, societies which used to be socialism-based, as it is the case with the Bulgarian one, accented on using terms and definitions, such as "human resources" and "human resources development". In contrast, it was as early as 1960s, when the terms "human capital", "investments in human capital",

\footnotetext{
*The paper is based on a nationwide research in the period 2007-2009, and on the $\mathrm{PhD}$ paper of Atanas Vladikov conducted 2010-2013.

**Correspondence to: Atanas Vladikov, 3 Lev

Tolstoi str., ap. 12, bl. 4710, entr. A, Plovdiv-4000,

BULGARIA, 00359.884.37.37.23,

avladikov@gmail.com
}

"returns on human capital", and others started to appear in articles, text-books, magazines, and in general and specific publications in developed countries, such as the US, for instance.

It was Richard Goode [Goode, 1959] the one to give the first definition of the term "human capital", which definition, in essence, stands to mean accrued knowledge, skills, and attitudes to perform better on the labor market. Early understandings of what "human capital" is, evolved in time, thankfully to Schultz [Shultz, 1961], Becker [Becker, 1962; Becker, 1964], Weisbrod [Weisbrod 1966], Mincer [Mincer 1974], and others. Later on, pleiades of academic researchers around the globe contributed much to the evolvement of the Theory of Human Capital, as a useful explanatory tool for numerous economic phenomena, nowadays.

Due to the nature of socialistic regiment, on the one hand, educational attainment at all levels in Bulgaria used to be free of charge to individuals, and, consequently, there is no adequate statistical evidence, nowadays, to calculate the educational costs back for the 
years before the political changes in Bulgaria in 1989.

On the other hand, in economies, such as the Bulgarian, the command-administrative mechanisms, applied before 1989, to deploy labor force by sectors of the national economy (having in mind that private ownership of factors of production, and private management Ire abolished and criminalized), and to regulate wage levels in a command-driven way, distorted not only the true labor relations, but also the incentives to work productively.

In addition to that, the term "educational market" was non-existent in Bulgaria, which is not the case in the present days, where I differ, in general: market of educational services, where investments in human capital may occur, and market of labor, where returns on human capital may accrue.

And it was as late as 2007, when a nation-wide representative academic research was conducted in Bulgaria to investigate the issues, related to human capital formation on the market of higher education, and this human capital consequential use on the labor market ${ }^{1}$.

Thus, the academic research I conducted is based on the concept that the market of education and labor market do have certain relation, which may be measured in monetary values. Here is why, I tested whether the Bulgarian reality corresponds to the lines of reasoning, set in the Theory of Human Capital, that: first, the greater the investments in acquiring knowledge and skills, the greater the rate of return on human capital, and, second, the longer the period of investment, the greater the rate of return on human capital. Moreover, the research, being comprehensive one, managed to distinguish certain steady processes of emerging innovative companies, which bring competitive wage gains to individuals, who happen to supply the labor market by certified accrued specific knowledge and skills.

\section{METHODOLOGY OF THE RESEARCH}

The research was conducted in three phases. The first phase was deemed to design the working tools /questionnaires/ and to conduct a

\footnotetext{
$\mathbf{1}_{\text {The author refer to the academic research: "Market }}$ Evaluation of Public and Private Investments in Human Capital, Formed in the Degrees of Higher Education", funded by the National Fund "Scientific Researches" of the Ministry of Education and Science of Bulgaria. The research is a 3-year project [ June/2007-June/2009].
}

nation-wide research among a specific target group - individuals of up to 39 years of age, who have higher education degrees, and work either in the private, or in public sector. There were two information cards - one for the companies in the private sector, and another for the organizations in the public sector. There were replies from 262 companies acting in the private sector and from 162 organizations acting in the public sector.

The information cards were designed to collect both general, and specific information of the characteristics of the actual levels of remuneration, employment statuses, career advancement of personnel, and others.

In addition to the two types of information cards, there were two sets of questionnaires distributed, as well. The first questionnaire was aimed at interviewing employed individuals, who meet the following three criteria: (1) to have higher education, (2) to be up to 39 years of age, and (3) to occupy executive positions; there were extensive interviews of 458 executives. The second questionnaire was designed to interview employed individuals, who meet the following criteria: (1) to have higher education, (2) to be up to 39 years of age, and (3) to be employed in either private or public sector on non-executive positions; there were 1,851 individuals questioned.

The second phase of the research included investigation of specialized literature and findings on the problem of investment-returns nature in terms of human capital formation and use globally, and domestically.

The third phase of the project included design of models to estimate the returns on human capital, as a result of human capital formation on the Bulgarian market of higher education, and its later use on the Bulgarian or other markets of labor. In addition to this challengeable estimation, a rating scale for market evaluation of the quality of higher education was planned to be constructed. The aim of constructing this rating scale was to structure in an adequate, modern, and realistic way the institutions of higher education in Bulgaria in terms of human capital formation.

I believe that best performing students would best perform on the labor market, in terms of levels of remuneration. Another important aspect of the level of usage of human capital is the issue, related to whether there are enough innovative companies and/or organizations on the Bulgarian market, that are prepared to provide cutting-edge work placements and 
highly-paid jobs to well-educated professionals.

\section{FINDINGS}

According to the present system of higher education degrees in Bulgaria, there are four levels of educational attainment, and four corresponding degrees: Specialist Degree (SD, 2-3 years of educational attainment); Bachelor Degree (BD, 4 years of educational attainment); Master Degree (MD, 5 years of educational attainment); and $\mathrm{PhD}$ Degree (PhDD, 8-9 years of educational attainment).

Of all collected responses, it was found that: $7,0 \%$ of questioned employees have SD; $32,9 \%$ of questioned employees have BD; $59,1 \%$ of questioned employees have MD; $0,3 \%$ of questioned employees have $\mathrm{PhDD}$;

A large number of interviewed - 95\%, responded that have graduated higher education after 1991; and $78 \%$ of all interviewed have stated that have legitimate qualification for the job they do (they may present a degree document, corresponding to their present professional occupation). And, the educational profile of questioned individuals, differentiated by area of professional degrees, has the following pattern: $36,4 \%$ of questioned individuals were professionals in economics; 22,8\% were professionals in technical sciences; $10,0 \%$ were professionals in nature sciences; $9,2 \%$ in management and administration; $8,6 \%$ - in computer science; $8,0 \%$ - in humanities; $6,4 \%$ - in educational science; $5,2 \%$ - in legal science; $3,2 \%$ - in other areas.

However, there were certain discrepancies between supply and demand, occurring on the real labor market, as $70,8 \%$ of employers in Bulgaria expressed their vision that the most demanded group of professionals, having higher education degree, is the group of Information Technology /IT/ professionals. Also, $64,1 \%$ of Bulgarian employers consider the second most demanded group of professionals to be the professionals having degrees in economics and administration. And finally, $56,3 \%$ of Bulgarian employers consider engineers to be the third most demanded group of professionals on the market. Therefore, free functioning of the labor market mechanism in Bulgaria would happen to favour in terms of monetary remuneration certain professional groups, who may benefit much from their knowledge, not only in domestic plan, but also in EU-28 megaeconomy.
If I place the findings for the Market of Education (ME) and the Market of Labor (ML) on a single radar graph /Graph-1/, I may observe strong deficits on the Bulgarian labor market in terms of certain groups of professionals, such as professionals in Economics, in Computer Science, in Technical Science, in Legal Science, and others.

Graph 1 Disequilibria between the (ME) and (ML) in Bulgaria

According to the national statistics, there are 51 Higher Education Institutions /HEIs/ and the ratio between the population of Bulgaria and the number of these HEIs is 149'520, that is, to one University/College, there are 149 '520 individuals. In addition to that, $70 \%$ of the population of the country between 24 and 65 years of age has high-school diploma, and about $21 \%$ of the very same age group has higher education degree, presently. Thus, I consider that Bulgaria is in a situation of deficit of highly-qualified professionals, which is expected to get greater. I think that this will be one of the main problems for the Bulgarian economy in a very near future.

A second problem is the exact estimation of the so-called human capital endowment of the country. The Economist estimated that the human capital endowment per employee on the average in the Western Europe (EU15) is about $\$ 240,000$ USD, while this figure is about $\$ 156,000$ for Slovenia, and as low as $\$ 75,000$ USD for Bulgaria and Romania (2007) ${ }^{2}$.

Public expenditures per student in the Bulgarian system of state-funded HEIs (which comfort as many as $95 \%$ of all enrolled) are set in a command-administrative way, top-tobottom, neither based on market demand, nor on market cost induction, nor onto adequate market price setting. In general, there are 9 higher educational fields of studies, which are assigned certain coefficients (administratively defined), which depend on the so-called "Base Costing Standard"/BCS/, which was set in 2009 to be 963 BGN /€ 491/ per student per academic year.

This BCS and the corresponding coefficients for each field of studies in the system of Bulgarian HEIs regulate the annual academic costs for the enrolled students in the statefunded HEIs.

Table 1 illustrates that higher education attainment in Bulgaria is not any more a "cheap" educational service, as it used to be in

${ }^{2}$ Economist, 19 Oct. 2007, The BrainpoIr Famine Begins to Bite 
times of socialism. Therefore, to me, the problem with the cost of human capital formation is critical to economic development of Bulgaria. Given the fact that the overall enrollment in the state-funded HEIs in Bulgaria varies between 250,000-260,000 students (2009), it may be easily computed the direct costs of human capital formation in Bulgaria in the tertiary sector. As there are additional indirect costs, which affect human capital formation in the tertiary sector of Bulgaria, and missed opportunities of an individual to accrue monetary benefits on the labor market, I believe that estimations, provided by "The Economist" on the human capital endowment, are correct to a great extent.

Table 1. Cost Standards for Higher Education Majors in State-Funded HEIs (2009) ${ }^{3}$

\begin{tabular}{|l|l|l|l|l|}
\hline & $\begin{array}{l}\text { Higher Educational Fields of Studies } \\
\text { Base Costing Standard =963 BGN /€491/4 }\end{array}$ & Coefficients & $\begin{array}{l}\text { Cost per Student } \\
\text { per Year /BGN/ }\end{array}$ & $\begin{array}{l}\text { Cost per Student } \\
\text { per Year /EUR/ }\end{array}$ \\
\hline 1 & Education, Economics, Tourism & 1,00 & 963.00 & $€ 491$ \\
\hline 2 & Sociology, Philology, History, Legal Studies & 1,60 & $1^{\prime} 520.80$ & $€ 776$ \\
\hline 3 & Mathematics, Technical Sciences & 2,30 & $2^{\prime} 214.90$ & $€ 1^{\prime} 130$ \\
\hline 4 & Veterinarian Studies, Agricultural Science & 4,30 & $4^{\prime} 140.90$ & $€ 2^{\prime} 113$ \\
\hline 5 & Arts & 5,00 & $4^{\prime} 815.00$ & $€ 2^{\prime} 457$ \\
\hline 6 & Sports & 6,20 & $5^{\prime} 970.60$ & $€ 3^{\prime} 046$ \\
\hline 7 & National Security & 7,81 & $7^{\prime} 521.03$ & $€ 3^{\prime} 837$ \\
\hline 8 & Human Medicine & 9,40 & $9^{\prime} 052.20$ & $€ 4^{\prime} 618$ \\
\hline 9 & Military Studies & 10,57 & $10^{\prime} 178.91$ & $€ 5^{\prime} 193$ \\
\hline
\end{tabular}

I employed the Model of Becker [Becker, 1962 and 1964] to estimate the net present value /NPV/ of an individual, who have gained academic degree in a Bulgarian HEI, and its internal rate of return /IRR/ on the labor market, as IRR is computed as a percentage of net increase per annum. In terms of definitions used, I employed the term "human capital" in the way described by the Bowles, Gintis, and Osborne [Bowles, Gintis, Osborne, 2001], namely that human capital is an individual's abilities to help the production process. And I looked on the investment process for human capital formation the way Becker looks on it [Becker, 1962], that is, investments include direct educational costs, indirect costs, and missed opportunities for wage induction or minimized wages received, during the period of educational attainment.

Also, I employed the term "returns on human capital investments", as it was defined by Rephann that there are two determinants of the returns on human capital: (1) cost of education, and (2) job opportunities after graduation.

\footnotetext{
${ }^{3}$ This table is based on an Internal Costing Report (2009) of the Ministry of Education, Science, and Youth of Bulgaria

${ }^{4}$ Here is the place to stress upon the fact that the Base Costing Standard /BCS/ is administratively imposed by the Council of Ministers onto all state-funded and staterun Colleges and Universities. It has to be underlined that for the years 2010-2013 the BCS was administratively diminished from 963 BGN to 693 BGN. This change is large enough to substantially alter the IRR downwards. For the sake of keeping the paper up to the true researched values, all computations have been executed with the 963 BGN BCS.
}

There have been early papers on investigating the returns on human capital ([Becker, 1964], [Mincer, 1974], [Ashenfelter \& Krueger, 1994], [Psaharopoulos, 1994], [ Dearden, 1998], [Ashenfelter, Harmon, Oosterbeek, 1999], [Arias \& McMahon, 2001], [Wilson, 2001] and others), where the rates have been estimated to vary from as low as $5 \%$ to $28 \%$ on annual basis. Additional contribution to the ways of computing the exact rates of returns on human capital in some developed states is the Report of the OECD (2002) ${ }^{5}$. These returns vary from state to state, but in any case, the rates of returns are highest in the UK and the US (in the range $13 \%$ and $18 \%$ for different indicators), compared to other countries' returns on human capital, such as Denmark, Italy, Germany, The Netherlands, and others (in the range of $7 \%$ to $14 \%$ approximately).

In order to compute the Present Value (PV) of human capital formation, I used the following formula:

$$
P V(Y)_{D}=\sum_{j=1}^{n} \frac{Y_{D}}{(1+r \%)^{j-1}}
$$

Where:

Present Value (PV) of future incomes, called Yields (Y), as a result of higher education Degree (D) would be a sum of the discounted

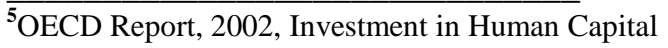
Through Post-Compulsory Education: The Impact of Government Financing, http://www.oecd.org/dataoecd/22/42/34949912.pdf, p.12, Table-4. Information retrieved on: 28.04.2010.
} 
Yields (Y) at a discounting rate $(\mathrm{r} \%)$ for a number of years (n), which period starts from a certain year (j). Then, I proceeded to compute the Net Present Value (NPV), considering the Investments (I) in higher education:

$$
N P V(Y)_{H D}=-I+\sum_{j=1}^{n} \frac{Y_{D}}{(1+r \%)^{j-1}}
$$

Thus, every time, when:

$$
N P V(Y)_{H D}>P V(Y)_{D}
$$

it is worth investing in acquiring knowledge and skills on the educational market as educational benefits from tertiary education on the labor market happen to be greater than the benefits, which may occur on the labor market without tertiary education.
Simulating a series of values, I came to the conclusion that the NPV of a Bulgarian professional would follow the theoretical investment-return curve, explained by Becker [Becker, 1962 and 1964]. However, due to the fact that the Bulgarian economy is, firstly, still in a period of transition, and, secondly, accessed as a full-member to the EU, the NPVvalue would greatly vary. Thus, the rate of return on human capital, measured through the internal rate of return /IRR\% would greatly vary, as well.

The following Table 2 of simulated results may be presented for a Bulgarian professional, who obtained his/her higher education degree on the Bulgarian educational market, and then worked for the period of all his working life on the Bulgarian market of labor.

Table 2. Human Capital Formation /NPV/ and Return /IRR\%/ in Bulgaria (2009)

\begin{tabular}{|l|l|l|l|l|l|l|l|}
\hline $\begin{array}{l}\text { Starting Monthly } \\
\text { Salary (in } € \text { ) }\end{array}$ & $€ 150$ & $€ 250$ & $€ 400$ & $€ 500$ & $€ 1^{\prime} 000$ & $€ 1^{\prime} 500$ & $€ 2^{\prime} 500$ \\
\hline $\begin{array}{l}\text { Starting Monthly } \\
\text { Salary (in BGN) }\end{array}$ & 300 & 500 & 800 & $1^{\prime} 000$ & $2^{\prime} 000$ & $3{ }^{\prime} 000$ & $5^{\prime} 000$ \\
\hline $\begin{array}{l}\text { NPV (in BGN, } \\
\text { in thousands) }\end{array}$ & 300 & 560 & 951 & $1^{\prime} 212$ & $2^{\prime} 500$ & $3^{\prime} 800$ & $6^{\prime} 400$ \\
\hline \begin{tabular}{l} 
IRR\% \\
\hline
\end{tabular} & $7 \%$ & $10 \%$ & $14 \%$ & $17 \%$ & $30 \%$ & $42 \%$ & $67 \%$ \\
\hline
\end{tabular}

As it may be observed from Table-2, simulations onto true costs of higher education, and true salaries in the Bulgarian economy, as of 2009 and 2010, would make NPV (the expected value of human capital of a Bulgarian who had received his/her tertiary education on the Bulgarian educational market) vary from as low as BGN 300,000 ( $€ 153,061)$ to about BGN 6,4 mln. (€ 3,265,306).

Also, the IRR\% would be not less than $7 \%$ per an individual with an academic degree, who successfully occupies a position on the Bulgarian labor market. I think that the IRR\% of a Bulgarian graduate would be greater than $10 \%$, as I used the returns on human capital in Belarus, as a benchmark; returns on human capital in Belarusian economy have been estimated at $10.1 \%$ per year [Pastore F., Veraschagina A., 2006].

And, based on the responses, I found the following pattern of salary levels among interviewed:

- $23,1 \%$ of all respondents marked monthly salary rate of: BGN 300-400 (€153-204);

- $21,9 \%$ marked monthly salary rate of: BGN 401 - 499 (€205-255);

- $29 \%$ marked monthly salary rate of: BGN 500 - 1,100 BGN (€256-561);
- The average monthly salary rate of all who have Bachelor's Degree and Master's Degree is: BGN 665 (€339);

Therefore, it will be more accurate to say that given the pre-conditions of the model, and serious changes in prices (as a result of Bulgaria's accession to EU and the global financial crisis), a true IRR\% will be in the range of $14 \%-17 \%$.

However, due to the fact that many educated Bulgarians now have the chance to work for foreign companies, working on Bulgarian soil, or to move to a country, member of the EU-28 for greater monetary incentives, then this IRR\% may jump to levels equal or more than $65 \%$ (that is, this individual to receive, for example, a net salary of $€ 2,500$ per month in Germany, UK, France, or other developed economy).

The private sector of the economy of Bulgaria before 1989 was, virtually, non-existent, while nowadays (2015), it is better developed than the public sectors, and it provides jobs to $66,4 \%$ of all professionals, having higher education. Employment of individuals having higher education has been detected to look in the following way (the research did not test job placements in the agricultural sector, as true 
levels of remuneration are desperately low and may not attract highly educated professionals to occupy jobs in this sector for long-term periods): $33,2 \%$ are employed in the industry sectors of the economy; $42,1 \%$ - in the private services sector; and $24,7 \%$ - employed in the public services sector (public administration).

Distribution of employees by enterprises follows this scheme: $28,8 \%$ of individuals having higher education are employed by enterprises, which employ between 10 and 50 individuals; $37,0 \%$ of individuals having higher education are employed by enterprises, which employ between 51 and 99 individuals; and $34,2 \%$ of individuals having higher education are employed by enterprises, which employ between 100 and 500 individuals.

Based on these findings, I think that there are very intensive processes of human capital formation within Bulgaria, fuelling a constantly increasing brain-drain process. In fact, I found that higher education attainment in Bulgaria is a very expensive activity, which helps mainly the private sector $(66,4 \%$ of graduates go to the private sector). In addition to that, true levels of salaries of these highlyqualified graduates are extremely low, compared to salary levels in developed countries of the EU-28. Thus, I think majority of individuals would play the strategy of minimizing their costs of educational attainment, and maximizing their gains from the labor market; that is, they will look for jobs, offered by foreign (non-Bulgarian) companies, operating in Bulgaria, or for jobs outside Bulgaria.

I also observed that only $10 \%$ of Bulgarian graduates reach top-management positions within Bulgarian companies/organizations (Table 3).

Table 3. Assignments of Bulgarian Graduates on Job Duties in the Companies/Organizations

\begin{tabular}{|l|l|}
\hline Job Duties & $\%$ of Interviewed Assigned \\
\hline Professionals on Top Management Duties & $9,98 \%$ \\
\hline Professionals on Applied Knowledge Duties & $17,22 \%$ \\
\hline Professionals on Analytical Job Duties & $68,19 \%$ \\
\hline Professionals on Other Duties & $4,61 \%$ \\
\hline
\end{tabular}

Majority of graduates $-68,19 \%$, were assigned to do analytical jobs, while another $17,22 \%$ were assigned on applied knowledge duties. However, $75,2 \%$ of interviewed stated that they had self-financed additional professional qualifications they needed to either career advance, or keep their job placement. It is interesting to observe the levels of individual self-financing (in addition to formal education) in the Bulgarian economy (Table 4).

Table 4. Declared Individual Expenses for Obtaining Professional Qualification (2007)

\begin{tabular}{|l|l|}
\hline Interviewed & Range \\
\hline $43,4 \%$ & up to 200 BGN $(€ 102)$ \\
\hline $28,5 \%$ & from 201 BGN to 400 BGN $(€ 103-€ 204)$ \\
\hline $16,6 \%$ & from 401 BGN to 600 BGN $(€ 205-€ 306)$ \\
\hline $7,3 \%$ & from 601 BGN to 800 BGN $(€ 307-€ 408)$ \\
\hline $8,9 \%$ & from 801 BGN to 1,000 BGN $(€ 409-€ 510)$ \\
\hline $3,4 \%$ & from 1,600 BGN to 2,000 BGN $(€ 816-€ 1,020)$ \\
\hline $2,6 \%$ & over 2,400 BGN ( over $€ 1,225)$ \\
\hline The currency rate is: $€ 1=1,96$ Bulgarian levs /BGN/ \\
\hline
\end{tabular}

This Table 4 confirms once again my viewpoint that education and training costs are quite high to the standard of living, on the one hand, and to the average monthly salary of a graduate. Thus, it is not surprising that only $10 \%$ to $13 \%$ of the for-profit companies in Bulgaria are considered innovative. Simply said, with a low level of investments, innovative businesses may not be developed and sustained in time. Although $70 \%$ of employers have stated that they provide goalsoriented training and qualifications to their staff, and although the fact that 58\% of employers declare that they provide on-the-job training, only $13,1 \%$ of Bulgarian enterprises have accumulated a share of IT-expenses of $11 \%$ to $26 \%$ from all production costs they incur. This stands to mean that the level of technological innovations of Bulgarian 
enterprises is very low and in full contrast to the New EU Strategy for Innovations.

On the one hand, the present condition of the economy may be analyzed "as it is", and this approach would definitely reflect the true interdependencies between material aspects of:

(1) capital accumulation;

(2) quality level of educational-qualification specifics of the human capital utilized; and

(3) influence of market factors and determinants, which induce stimuli or antistimuli to implement innovative technologies and to better re-design technological, production, organizational, and managerial systems of the enterprises;

I found that only $8,6 \%$ of Bulgarian enterprises have greater than the country's average expenses on acquiring know-how, licenses, patents. Due to inadequate investment culture in terms of technological advancement and human capital use, I expect Bulgarian companies and organizations to stay for long time unprotected to drift currents of global and EU-28 economy. And also, due to misuse and/or underestimation of the formed human capital, Bulgarian companies will also lag behind their counter partners from the rest states, members of the EU-28.

The empirical research I conducted demonstrates that there are too many imperfections in formation and use of human capital in Bulgaria, as the standards of living of most of the EU members are higher than the standard of living in Bulgaria. At present, the country is a brain donor to the greater EU labor market as the highly qualified individuals (graduates with higher education) enjoy higher rates of return from working outside Bulgaria, but within the EU. This is a trend, which is reasonable to assume to stay unchanged for a comparatively longer period, as there are no real signs for a high positive economic growth in Bulgaria in the next decade.

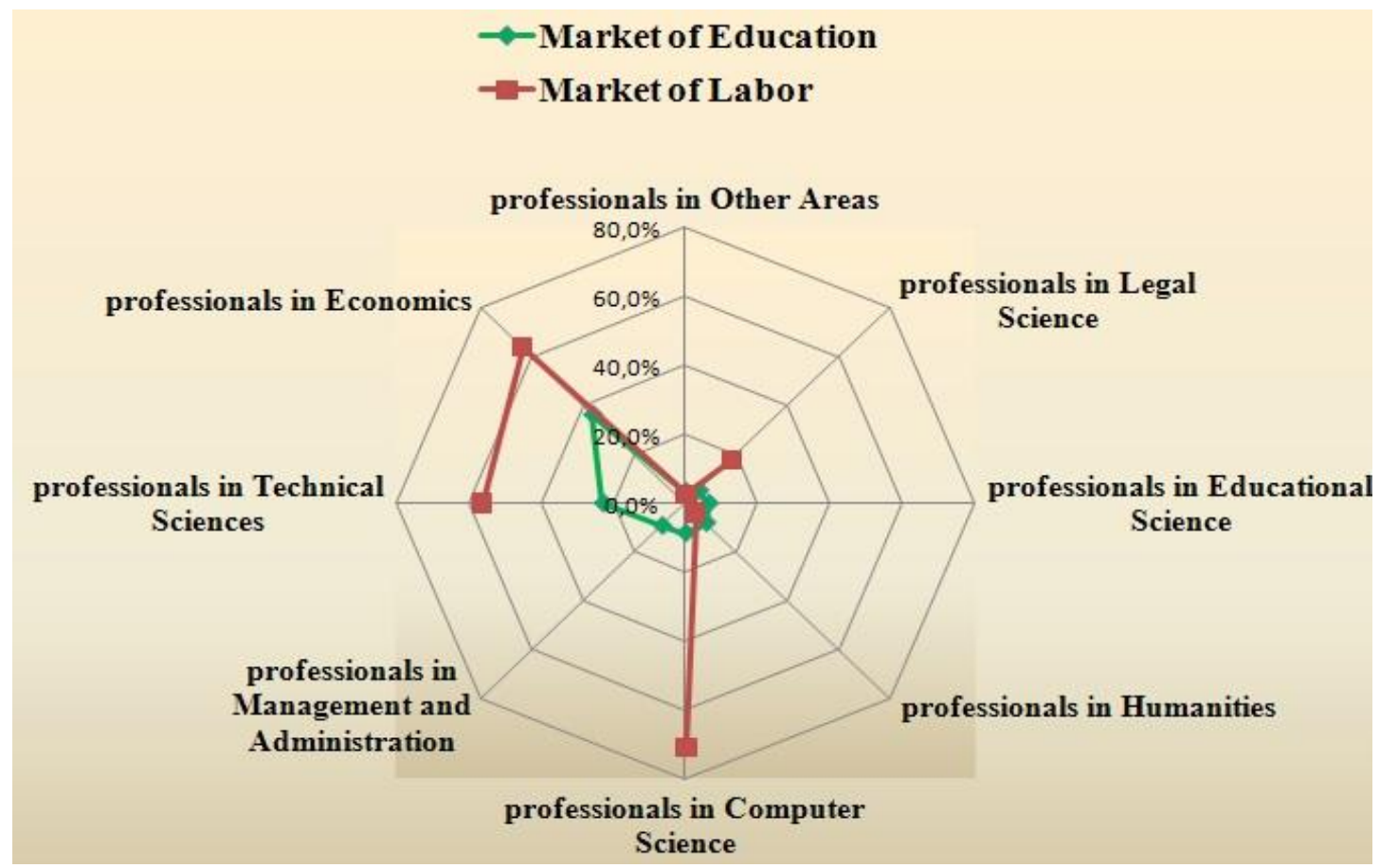

\section{REFERENCES}

1. Ashenfelter O., Krueger A., Estimates of the Economic Return to Schooling from a New Sample of Twins, American Economic Review, 84(5), p. 1157-1173, 1994.

2. Ashenfelter O., Harmon C., Oosterbeek H., A Review of Estimates of the Schooling/Earnings Relationship, with Tests for Publication Bias, Labor Economics, 6(4), p. 453-470, 1999.

3. Arias O., McMahon W., Dynamic Rates of Return to Education in the US, Economics of Education Review, 20(1), p. 121-138, 2001.

4. Becker G., Investment in Human Capital: A Theoretical Analysis, Journal of Political Economy, 70(5), p. 9-49, 1962.

5. Becker G., Human Capital: A Theoretical and Empirical Analysis with Special Reference to Education, Columbia University Press, New York, 1964.

6. Bowles S., Gintis H., Osborne M., The Determinants of Earnings: A Behavioral Approach, Journal of Economic Literature, 39(4), p. 1137-1176, 2001. 
7. Dearden L., Ability, Families, Education and Earnings in Britain, Institute for Fiscal Studies, 98/14, 1998.

8. Goode R., Adding to the Stock of Physical and Human Capital, American Economic Review, 49 (2), p.147-155, 1959.

9. Mincer J., Schooling, Earnings, and Experience, Columbia University Press, New York, 1974.

10.Pastore F., Veraschagina A., Private Returns to Human Capital over Transition: A Case Study of Belarus, Economics of Education Review, 25, p. 91-107, 2006.

11.Psaharopoulos G., Returns to Investment in Education: A Global Update, World Development, 22(9), p. 1325-1343, 1994.
12.Rephann T., The Importance of Geographical Attributes in the Decision to Attend College, Socio-Economic Planning Sciences, 2002.

13. Schultz T., Investment in Human Capital, American Economic Review, 51 (1), p.1-17, 1961.

14. Weisbrod B., Investing in Human Capital, Journal of Human Resources, 1(1), p. 5-21, 1966.

15.Wilson K., The Determinants of Educational Attainment: Modeling and Estimating the Human Capital Model and Education Production Functions, Southern Economic Journal, 67(3), p. 518-551, 2001. 